This is a post-print version of the following published paper:

PACTE Group, Amparo Hurtado Albir (principal investigator), Anabel Galán-Mañas, Anna Kuznik, Christian Olalla-Soler, Patricia Rodríguez-Inés \& Lupe Romero (research team, in alphabetical order) (2018) "Competence levels in translation: working towards a European framework", The Interpreter and Translator Trainer, 12:2, 111-131, DOI: 10.1080/1750399X.2018.1466093

Link to this article: https://doi.org/10.1080/1750399X.2018.1466093

\title{
Competence levels in translation: working towards a European
}

\section{framework}

This paper presents the research project the PACTE group is carrying out on "Establishing Competence Levels in the Acquisition of Translation Competence in Written Translation". A continuation of PACTE's previous experimental research on translation competence and its acquisition, the project aims to propose level descriptors as a first step towards developing a common European framework of reference for translation's academic and professional arenas, both of which are represented among its participants. The project is organized into three stages, the first of which involved the production of a first level descriptor proposal, including a three-level scale with sub-levels and five descriptive categories (language competence; cultural, world knowledge and thematic competence; instrumental competence; translation service provision competence; and translation problem solving competence). In the second stage, the proposal produced is to be evaluated by experts from the academic and professional arenas. In the third stage, the data obtained through the expert judgement process will be analysed and the proposal revised. This paper sets out the project's objectives, our grounds for undertaking it, its conceptual framework and its methodology, as well as the results obtained in the first stage and the future direction of the research.

Keywords: competence levels, European framework, descriptor scales, translation competence, translation competence acquisition

\section{Introduction}

The aim of this paper is to present the research project the PACTE group is carrying out 
on "Establishing Competence Levels in the Acquisition of Translation Competence in Written Translation" (NACT, based on the project's initials in Spanish), funded by Spain's Ministry of the Economy and Competitiveness (FFI2013-42522-P).

The objective of the NACT project is to describe performance levels in translation, as a first step towards developing a common European framework of reference for use in translator training and professional translation. In terms of its goals and approach, this framework should be similar to the CEFR (Common European Framework of Reference for Languages). Additionally, the levels of the CEFR will be used to establish the language competence levels corresponding to each translation level, thus making a clear distinction between language competence levels and translation levels.

As the project is a first step towards establishing performance levels in translation and has a duration of just four years, it does not extend to describing translators' different specialized professional profiles (legal translation, economic and financial translation, technical translation, scientific translation, literary translation, etc.), which is a task for a future research project. The levels it describes cover preprofessional translation and the generalist professional translator profile.

The project's research is a continuation of PACTE's previous experimental investigations into translation competence and its acquisition (see Hurtado, 2017a, PACTE, 2014, 2015, submitted). Actors from translation's academic and professional arenas are participating in the project.

This paper presents the project's objectives, our grounds for carrying it out, its conceptual framework and its methodology, as well as our first level descriptor proposal 
(including examples from level B2) ${ }^{1}$ and the future direction of the research. The paper includes the three annexes that complete the descriptor proposal.

\section{Research objectives}

The purpose of the research is to establish performance levels in written translation in the European context. Accordingly, its objectives are:

(1) To describe the specific competences involved in translation competence acquisition.

(2) To describe levels of performance in translation.

We aim to propose level descriptors as a first step towards developing a common European framework of reference, comparable to the CEFR for languages, for use in translator training and professional translation.

As stated previously, the project involves describing not translators' specialized professional profiles but the levels corresponding to pre-professional and generalist professional translators.

Rather than learning outcomes and criteria for each stage of education or area of professional practice, the research aims to propose performance levels that could be used according to each educational or professional context's needs. The description of competence levels is independent of language combinations and directionality (direct translation, to L1; inverse translation, to L2). It is also independent of the number of hours involved, as this is a curricular consideration.

1. See PACTE in press for a full presentation of all the level descriptors. 


\section{Grounds for the research}

Translation Studies lacks a common description of competence levels, in contrast to other disciplines and the way the CEFR, for example, describes such levels for language teaching. Translation needs such a description for various reasons.

In the academic arena, there are different levels of translator training in university education (undergraduate and master's degrees) and non-university education. Criteria regarding the necessary levels of training vary greatly. The levels attained in earning the same qualification (an undergraduate or master's degree) can be very different in different centres and countries. Additionally, there are countries in which translation is not taught as a specific training programme, only as part of other programmes (languages, philology, etc.), resulting in potential dissimilarities between the levels of training reached. Requirements for academic standardization within the European Higher Education Area, entailing homogenization and transparency in each centre's training levels, are also an important factor to bear in mind.

In the professional arena, there are different performance and specialization levels in the translation market (professional and non-professional translators of various kinds and at various levels). Furthermore, the globalization of this market is generating a need for greater precision as regards the level of performance each translator can guarantee and the requirements to be met in each case.

Increasing academic and professional mobility in the translation sphere is another factor in requirements for precision and transparency in relation to the performance levels possible.

A common framework would facilitate comparison between different grading systems and would serve as a guide for creating translation study programmes; designing assessment procedures (exams, formative and diagnostic assessment); 
producing textbooks and teaching materials; issuing official certificates; recognizing and validating academic qualifications; establishing professional and academic profiles; and establishing professional quality control criteria.

Lastly, there is a need to clearly establish the differences between levels of language competence and levels of translation competence.

\section{Conceptual framework}

Our research has a dual conceptual framework: (1) research on translation competence and its acquisition; and (2) research on descriptor scales. The main sources on which the research is based are indicated below.

\subsection{Translation competence (TC) and translation competence acquisition (TCA)}

Firstly, our research draws on proposed descriptions of TC and TCA developed in the academic and professional arenas ${ }^{2}$.

In particular, it draws on the results of two of PACTE's previous experimental research projects. The first was on TC, and compared the performance of 35 professional translators and 24 foreign-language teachers (Hurtado, 2017a). The second was on TCA, and analysed a sample of 130 trainee translators (undergraduate degree students) (PACTE, 2014, 2015, submitted). These two projects served to validate PACTE's TC and TCA models (see PACTE, 2000, 2003, 2014).

We have also considered the translator competence profile of the EMT (European Master's in Translation), drawn up by a group of experts in 2009.

2. For a review of models of TC, see Hurtado ([2001] 2011, 382-400, 2017b, 18-33) and Koby and Melby (2013). For a review of models of TCA, see Hurtado ([2001] 2011, 401-408). 
In addition, we have studied competence descriptors produced in the professional translation sphere, specifically:

- The description of professional translators' competences according to the UK's National Occupational Standards.

- The set of competences which the Vertaalacademie Maastricht and PSTEVIN (a platform encompassing the professional associations of translators of the Netherlands) developed in 2011 and revised in 2016.

- The description of levels for translator certification produced by NAATI (Australia's National Accreditation Authority for Translators and Interpreters), which is currently being revised: Improvements to NAATI Testing (INT).

We have also referred to the description of the ATA (American Translators Association) certification programme and the ITI (Institute of Translation and Interpreting) Code of Professional Conduct.

We have thus been able to observe which competences are most often required of translators in the proposals in question and, while there are very few competence level proposals, what the levels and names they put forward are (see Table 1). The results of PACTE's experiments have especially enabled us to identify which competences are essential and how they develop, and to define descriptors related to strategic abilities for solving translation problems, extralinguistic knowledge and instrumental competence. Our definition of aspects related to professional competences has been particularly based on the proposals of the EMT, NAATI and the UK's National Occupational Standards in Translation.

For our description of cultural aspects, we have also referred to: 
- The PICT (Promoting Intercultural Competence in Translators) project's

curriculum framework for intercultural competence (2012).

- The intercultural competence model put forward by Yarosh (2012) and the

learning outcomes described for each sub-competence (Yarosh, 2015).

- The elements of intercultural competence proposed by the INCA (Intercultural

Competence Assessment) project (2009).

- The plurilingual and pluricultural competences of the extended version of the

CEFR (Council of Europe, 2016 [pilot version]).

Table 1. Main reference sources used

\begin{tabular}{|c|c|c|}
\hline SOURCE & COMPETENCES & LEVELS \\
\hline $\begin{array}{l}\text { PACTE }(2000, \\
2003)\end{array}$ & $\begin{array}{l}\text { - Bilingual competence } \\
\text { - Extralinguistic competence } \\
\text { - Knowledge of translation } \\
\text { - Instrumental competence } \\
\text { - Strategic competence } \\
\text { - Psycho-physiological components }\end{array}$ & - \\
\hline $\begin{array}{l}\text { National } \\
\text { Occupational } \\
\text { Standards in } \\
\text { Translation (Skills } \\
\text { CFA, 2007) }\end{array}$ & $\begin{array}{l}\text { - Maintain skills and systems for managing } \\
\text { translation tasks } \\
\text { - Manage new translation assignments } \\
\text { - Translate written texts from one language to } \\
\text { another } \\
\text { - Develop your performance as a professional / } \\
\text { an advanced professional translator } \\
\text { - Evaluate and improve translation services to } \\
\text { meet client needs } \\
\text { - Act as a mentor to trainee and colleague } \\
\text { translators } \\
\text { - Manage translation projects }\end{array}$ & $\begin{array}{l}\text { - Advanced professional } \\
\text { translator } \\
\text { - Professional translator }\end{array}$ \\
\hline EMT (2009) & $\begin{array}{l}\text { - Translation service provision competence } \\
\text { - Language competence } \\
\text { - Intercultural competence } \\
\text { - Information mining competence } \\
\text { - Thematic competence } \\
\text { - Technological competence }\end{array}$ & - \\
\hline $\begin{array}{l}\text { Vertaalacademie } \\
\text { Maastricht (2011, } \\
\text { 2016) }\end{array}$ & $\begin{array}{l}\text { - Translation competence (translation of texts) } \\
\text { - Language and textual competence } \\
\text { - Information location / documentation and } \\
\text { research competence } \\
\text { - Cultural competence } \\
\text { - Technological competence } \\
\text { - Business competence }\end{array}$ & $\begin{array}{l}\text { - Level } 3 \\
\text { - Level } 2 \\
\text { - Level } 1\end{array}$ \\
\hline $\begin{array}{l}\text { NAATI }(2016, \\
\text { currently being } \\
\text { revised) }\end{array}$ & $\begin{array}{l}\text { - Language competency } \\
\text { - Intercultural competency } \\
\text { - Research competency } \\
\text { - Technological competency } \\
\text { - Thematic competency } \\
\text { - Transfer competency }\end{array}$ & $\begin{array}{l}\text { - Certified advanced translator } \\
\text { - Certified translator } \\
\text { - Recognised translator }\end{array}$ \\
\hline
\end{tabular}




\begin{tabular}{|l|l|l|}
\hline & $\begin{array}{l}\text { - Service provision competency } \\
\text { - Ethical competency }\end{array}$ & \\
\hline
\end{tabular}

\subsection{Descriptor scales}

Secondly, we have drawn on research on descriptor scales, encompassing descriptive categories (set out horizontally) and level descriptors (set out vertically). In particular, we have referred to the CEFR's description of level scales for languages (Council of Europe, 2001), and have incorporated its levels into our description of language competence. Additionally, we have studied the description of "Translating" in the "Mediation" section of the extended version of the CEFR (Council of Europe, 2016 [pilot version]).

\section{Methodology and research stages}

The project has a four-year duration (2015-2018). Its research, which essentially involves qualitative methods, as well as descriptive quantitative methods, is organized into three stages.

\subsection{Participants}

The research involves different types of participants.

(1) Representatives of the academic translation arena (institutions and lecturers). A total of 23 European translator training centres from 15 countries contributed to the first stage of the project ${ }^{3}$. When selecting centres, we looked

3. The centres currently participating in the project belong to the following universities (in

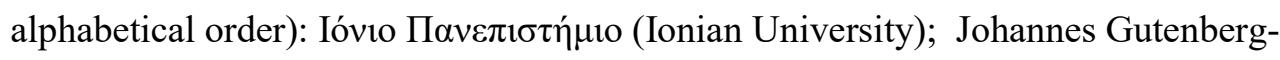
Universität Mainz; Open University; Stockholms Universitet; Universitatea Alexandru Ioan Cuza; Universiteit Antwerpen; Universitat Autònoma de Barcelona; Università di Bologna; University of Eastern Finland; Université de Genève; Universiteit Gent; 
to guarantee their experience in translator training and diversity in terms of languages, educational contexts and levels of education (undergraduate and master's degrees). We also took the inclusion of Spanish among their language combinations into consideration. The role of these participants is to provide information on their centres' curriculums and act as a panel of experts to evaluate the proposed level descriptors.

(2) Representatives of Europe's professional translation arena. Professional associations and generalist translators will be contributing to the project. Their role is to act as a panel of experts to judge the proposed level descriptors.

The research also involves two experts unrelated to translation who have contributed to the project in an advisory capacity. One is a specialist in establishing levels and the other in education project management. Additionally, the European Commission's Directorate-General for Translation (Spanish Language Department) is collaborating with the project.

\subsection{Research stages}

Stage one: production of a first level descriptor proposal (completed)

This stage was completed in May 2017. Its objective was to produce a first level descriptor proposal (see section 6. First results), to which end we performed the following tasks:

Universidad de Granada; Universität Hildesheim; Universitat Jaume I; Univerza v Ljubljani; Universidade Nova de Lisboa; Université Paris III; Università del Salento; Università degli Studi di Trieste; University of Westminster; Uniwersytet Wrocławski; Zürcher Hochschule für Angewandte Wissenschaften; Zuyd Hogeschool. 
(1) Compilation and analysis of 18 European translator training centres' undergraduate and master's degree curriculums ${ }^{4}$. We set up an online questionnaire and used the data obtained to create a database containing information on:

- The translation curriculums of 16 undergraduate and 26 master's degree programmes, specifically programme name, duration, number of L2s and L3s and corresponding entry levels, and specific and general competences.

- The translation courses involving English and/or Spanish (L1 or L2) of 9 undergraduate and 26 master's degree programmes (91 undergraduate and 124 master's degree courses), specifically semester(s) in which translation into L1 and translation into L2 are introduced; progression; and specific and general competences, learning goals, content and text genres used, and the progression established in each case.

(2) Compilation and analysis of proposals from the academic and professional arenas (EMT, NAATI, etc.; see section 4.1.) regarding the competences translators require.

(3) Production of a preliminary description of levels, which a group of experts in competence design and establishing competence levels evaluated.

(4) Production of a first level descriptor proposal, which was presented in March 2017 at a work session attended by representatives of the participating institutions and subsequently discussed further online.

(5) Revision of the first proposal, following face-to-face and online discussions with participants.

4. 18 centres provided curriculum information in this stage of the project. 
Stage two: evaluation of proposed level descriptors (2017)

In the second stage, which began in June 2017, expert judgement on the first proposed descriptors is to be sought from the academic and professional translation arenas.

In the case of the academic arena, we aim to collect information from up to five translation lecturers with different profiles in terms of experience in direct and inverse translation, teaching levels and language combinations from each participating centre. They must have solid experience in teaching direct or inverse translation and, if possible, some experience of curriculum design or programme coordination work. With regard to the professional arena, we will select up to 10 generalist translators with varying language combinations from each of the 15 countries involved in the project. Additionally, some of the language departments of the European Commission's Directorate-General for Translation will be involved. The chosen translators must translate in various areas (rather than specializing in a single area of professional practice) and have solid experience in direct or inverse translation. Additionally, translation must be their main occupation. We also envisage the participation of a maximum of two (non-specialized) professional associations of translators from each country ${ }^{5}$.

The tasks to be performed in this stage are as follows:

(1) Producing and administering three pre-selection questionnaires to ensure that the participating lecturers, translators and associations meet our requirements.

(2) Producing a questionnaire for the evaluation of the proposed descriptors.

5. Specialized associations (from the areas of legal translation, audiovisual translation, etc.) will be involved in future work to describe specialized professional profiles. 
(3) Pilot testing the questionnaire.

(4) Administering the questionnaire to approximately 100 representatives of the academic arena from the participating centres, and approximately 75 generalist translators and non-specialized professional associations of translators from the 15 countries involved in the project.

Stage three: questionnaire data analysis and proposal review (2018)

The objective of this stage is to analyse the data obtained through the expert judgement process and revise our level descriptor proposal. The tasks to be performed are as follows:

(1) Creating a database containing information from the evaluation questionnaire.

(2) Analysing the data obtained and revising the descriptor proposal.

\section{First results: production of a first level descriptor proposal}

As a result of the first stage of our research, we produced "Establishing competence levels in translation. Proposal 1"6, a bilingual (Spanish and English) document containing our first proposed level descriptors, in March 2017. We presented it at a meeting with representatives of the centres and institutions participating in the project in the Universitat Autònoma de Barcelona's Faculty of Translation and Interpreting on 16 March 2017, and subsequently created an online forum to enable the attendees to

6. This document has been produced with advice from Esther Adot, Catalan University Quality Assurance Agency (AQU Catalunya); Álvaro García Santa Cecilia, Cervantes Institute; Dorothy Kelly, Translation and Interpreting Department, Universidad de Granada; and Catherine Way, Translation and Interpreting Department, Universidad de Granada. 
continue their discussions. The ideas exchanged led us to make some changes to the proposal, involving, among other things, explaining its characteristics more explicitly and adding, rewording or altering the level of certain descriptors. It is this revised version of the first proposal on which expert judgement will be sought.

\subsection{Proposed levels}

Our proposal seeks to establish a number of levels which shows differences in terms of progress up the scale, as well as to remain within the levels a professional translator is capable of distinguishing and operating at. We have used a three-level scale with sublevels, following the example of the CEFR.

\subsubsection{A three-level scale}

Our proposed levels are:

- Translation level C. Competences corresponding to each professional profile (consolidation of areas of specialization in translation): specialist professional translator. We believe the professional areas that ought to be described are legal translation; economic and financial translation; technical translation; scientific translation; literary translation; audiovisual translation (dubbing, subtitling, voice-over); accessibility (audio description, subtitling for the deaf); and localization (web pages, software, videogames) ${ }^{7}$. Level $\mathrm{C}$ is only described in general terms as the areas of professional specialization have yet to be described.

7. We have not included certified or sworn translation, as such translation, which is performed by translators with official accreditation in some countries, can involve mastery of any area of specialization (legal, administrative, economic, scientific, technical, etc.). 
- Translation level B. Basic specialized translation competences (introduction to areas of specialization in translation): generalist professional translator.

- Translation level A. Basic translation competences (introduction to translation): pre-professional translator. At this level, an individual is not yet capable of carrying out professional translation projects or of matching a professional translator's level of performance ${ }^{8}$.

\subsubsection{Levels and sub-levels. Genres liable to be translated at each level}

Levels A and B are both divided into two sub-levels, A1 and A2, and B1 and B29 ${ }^{9}$ Level $\mathrm{C}$ has not been divided, and features just a general description.

The levels are accumulative, meaning that an individual at any given level is assumed to have mastered the previous one. The description of each level does not, therefore, repeat the previous level's descriptors.

For each level we have proposed text genres an individual should be able to translate:

- $\quad$ Translation level C (specialist professional translator). Specialized texts corresponding to at least one area of professional specialization (legal; economic and financial; scientific; technical; literary; audiovisual; accessibility; localization). It should be noted that the texts translated in some areas of specialization (audiovisual, accessibility and localization) are not always

8. We consider a professional translator to be a translator who performs translations regularly, capably and effectively.

9. 'Plus' sub-levels (e.g. B1+) could be added in the future, as they were in the case of the CEFR. 
specialized. In such cases, the specialized aspect of such work stems from the type of medium and the nature of the modality of translation involved.

- Translation level B2 (generalist professional translator). Semi-specialized texts (for a non-specialized target audience), of low terminological and conceptual difficulty, corresponding to at least one area of professional practice (legal and administrative; economic and financial; technical; scientific; non-literary publishing).

- Translation level B1 (generalist professional translator). Non-specialized texts, without terminological or conceptual difficulty, corresponding to at least one area of professional practice (legal and administrative; economic and financial; technical; scientific; non-literary publishing).

- Translation level A2 (pre-professional translator). Non-specialized texts of different types (narrative, descriptive, expository, argumentative, instructional) involving problems related to register (tenor, style).

- Translation level A1 (pre-professional translator). Non-specialized texts of different types (narrative, descriptive, expository, argumentative, instructional) in standard language.

We have produced an annex that gives examples of text genres liable to be translated at each level (see Annex 1). The progression we have established in terms of text genres is marked by increasing difficulty. For each level we have provided examples of genres an individual should be able to translate. In the case of level A, genres are organized into the following text types: narrative, descriptive, expository, argumentative and instructional. In the case of level B, they are organized into the following areas of generalist translators' professional practice: legal and administrative; economic and financial; technical; scientific; and non-literary publishing. In the case of 
level $\mathrm{C}$, they are organized into the following areas of professional specialization: legal; economic and financial; scientific; technical; literary; audiovisual; accessibility; and localization.

Where the same genres are included at different levels, they differ on the basis of other characteristics. Such differences are related to register in the case of levels A1 and A2. As far as genres (e.g. reports) repeated at levels B1 and B2 are concerned, the difference between them lies in their more or less specialized nature at each level.

\subsubsection{Particularity of level $C$}

As indicated previously, level $\mathrm{C}$ is a special case, as it ought to include a description of each area of professional specialization. To that end, we need additional information from professionals working in each such area and from specialized master's degree programmes for training them. In our proposal, this level is described in general terms, without details of each area's specific aspects other than a description of text genres. We have described the text genres to guide us in proposing where the boundaries between levels B and C should lie, as well as to remain within the levels a professional translator is capable of distinguishing and operating at. Further research is thus required for the purpose of describing level C.

\subsection{Descriptive categories}

The descriptive categories used are competences. The competences we put forward are those that appear most frequently in the proposals we have studied from the academic and professional translation arenas (see section 4.1), specifically language competence; cultural, world knowledge and thematic competence; instrumental competence; translation service provision competence; and translation problem solving competence. They are interrelated, and interact and balance one another out at each level. 
The fundamental characteristics of each category are presented below. The descriptors are formulated in terms of capability to act (can do) rather than of declarative knowledge, as they refer to performance levels within competences and describe the mobilization and application of knowledge. For merely illustrative purposes, in each case we include the description of level B2, as it is the highest level corresponding to generalist professional translators and the last we describe in this project.

\subsubsection{Language competence}

This is described in terms of reading comprehension in the source language and written production in the target language, in relation to the genres liable to be translated at each level, and with reference to the levels of the CEFR (Table 2). We propose a minimum of CEFR reading comprehension level $\mathrm{B} 2$ and written production level $\mathrm{C} 1$ for translation level A1, and of CEFR level C2 where both reading comprehension and written production are concerned for translation level C. Our proposals regarding levels can be justified on the basis of the profiles corresponding to each level. It is worth noting that, according to our analysis of curriculums from 18 centres (see 5.2), the minimum level of language competence required in most cases is level B2 of the CEFR.

Table 2. Language competence descriptors

\section{TRANSLATION LEVEL B2}

1. Can understand semi-specialized source language texts (for a non-specialized target audience) corresponding to at least one of translation's areas of professional practice (legal and administrative; economic and financial; technical; scientific; non-literary publishing), to which end a minimum of CEFR reading comprehension level $\mathrm{C} 1$ is required.

2. Can produce semi-specialized target language texts (for a non-specialized target audience) corresponding to at least one of translation's areas of professional practice (legal and administrative; economic and financial; technical; scientific; non-literary publishing), to which end a minimum of CEFR written production level $\mathrm{C} 2$ is required.

\subsubsection{Cultural, world knowledge and thematic competence}

This refers to an individual's mobilization of knowledge about their own culture and the 
foreign culture involved, as well as of (universal) world knowledge and thematic knowledge corresponding to specific fields, to solve translation problems (Table 3). The progression we have established in the difficulty of cultural references is related to their degree of explicitness in the texts in which they appear and the level of complexity of the knowledge needed (basic or advanced) to translate them. Individuals begin solving thematic aspects at level B1, and progress from mobilizing basic (level B) to specialized (level C) thematic knowledge.

Table 3. Cultural, world knowledge and thematic competence descriptors

\section{TRANSLATION LEVEL B2}

1. Can mobilize advanced knowledge about the cultures involved and identify their differences to solve problems related to explicit and implicit cultural references in semi-specialized texts (for a non-specialized target audience) corresponding to at least one area of professional practice.

2. Can mobilize advanced world knowledge to solve explicit and implicit problems related to such knowledge in semi-specialized texts (for a non-specialized target audience) corresponding to at least one area of professional practice.

3. Can mobilize basic thematic knowledge to solve translation problems in semi-specialized texts (for a non-specialized target audience) corresponding to at least one area of professional practice.

We have produced an annex that gives examples of cultural and world knowledge for levels A and B (see Annex 2). We have not established differences between $\mathrm{A} 1$ and $\mathrm{A} 2$ or between $\mathrm{B} 1$ and $\mathrm{B} 2$ as far as the type of declarative knowledge involved is concerned, as we feel there are no substantial changes in the type of extralinguistic knowledge required to translate these levels' genres. Furthermore, it would be difficult to guarantee significant changes in such knowledge from the perspective of learning to translate.

\subsubsection{Instrumental competence}

This refers to the use of documentation resources (types of resources and queries) and technological tools (Table 4). The progression we have established in the levels' descriptions refers to the use of documentation resources appropriate to each level's text genres; the type of queries performed (basic, complex); the technological tools used 
(basic, advanced); and the functions (basic, advanced) of such tools an individual is capable of using.

Table 4. Instrumental competence descriptors

\section{TRANSLATION LEVEL B2}

1. Can identify and use reliable documentation resources to solve translation problems in semispecialized texts (for a non-specialized target audience) corresponding to at least one area of professional practice; e.g. specialized search engines, general and specialized corpora, professional and specialized blogs and forums, consulting expert translators and specialists from other fields (language combination and context permitting).

2. Can perform complex queries in the aforementioned resources (e.g. using Boolean operators, restricting search criteria, using a resource's advanced search options), combining types of resources and queries.

3. Can use basic functions of specialized technological tools to solve translation problems in semispecialized texts (for a non-specialized target audience) corresponding to at least one area of professional practice; e.g. specialized search engines, computer-assisted translation, text alignment, corpus linguistics applied to translation (language combination and context permitting).

4. Can adapt to new documentation resources and technological tools.

We have produced an annex that gives examples of technological tools and functions for levels A and B (see Annex 3).

\subsubsection{Translation service provision competence}

This includes the management of aspects of professional practice and the workings of the labour market (Table 5). It varies according to the area of professional practice involved and the type of employment open to a translator (in a public body, in a translation agency, self-employment, etc.), so appropriate descriptors need to be considered on a case-by-case basis. The development of this competence largely begins at level B1, with level A only including basic aspects connected to translation briefs. In our proposal, level B1 includes basic aspects related to the translation profession, such as being able to identify the areas of employment open to translators, translation's areas of specialization, the tasks a translator might perform and the institutions involved in the practice of the profession.

Table 5. Translation service provision competence descriptors 
1. Can effectively meet the quality standards the labour market requires in each context for texts translated by a generalist translator in at least one area of professional practice.

2. Can meet the profession's ethical requirements (confidentiality, impartiality, turning down work beyond one's capabilities, etc.) when carrying out a translation task and when interacting with the actors involved in a translation project.

3. Can revise and post-edit translations of texts corresponding to a generalist translator, meeting the quality standards the labour market requires in each context.

4. Can use marketing strategies to capture and retain customers and obtain professional assignments. [If required in the relevant job]

5. Can negotiate with the actors involved in a translation project (customers, other professionals) to determine deadlines, rates, invoicing methods, working conditions, the nature of the contract involved, rights and responsibilities, the project's specifications, etc., and can fulfil the conditions established. [If required in the relevant job]

6. Can work in coordination with the actors involved in a translation project (customers, project managers, other translators, correctors, etc.) and maintain an efficient workflow. [If required in the relevant job]

7. Can determine a translation project's profitability on the basis of the workload, rate and deadline it involves. [If required in the relevant job]

8. Can produce quotes and invoices in accordance with established standards in different translation scenarios. [If required in the relevant job]

9. Can manage basic tax requirements (e.g. registration of professional activity, registration as an intraCommunity operator, quarterly or annual tax returns, withholding statements, statements of transactions with third parties), translation contracts and possible conflicts arising from non-payment (e.g. notifications, formal requests, "order for payment" procedures, legal proceedings). [If required in the relevant job]

10. Can manage workflow-related administrative tasks (e.g. recording and checking customers' details, rates applied, projects carried out, payment status). [If required in the relevant job]

11. Can manage the physical working environment (e.g. workplace location, lighting conditions) and virtual working environment (e.g. screen organization, folder management, tool maintenance).

\subsubsection{Translation problem solving competence}

This refers to the types of translation problems liable to be solved at each level (Table

6). It is the central category as, in determining the competences required at each level, it

has a bearing on all the other categories. It is directly related to the text genres an

individual should be able to translate at each level.

We have established a progression in terms of the difficulty of the problems to

be solved at each level. Individuals should be capable of solving basic language

interference problems at level A1 and problems stemming from language variation at

level A2. Intentionality is introduced at level A2, and thematic problems and problems

stemming from professional translation briefs are included as of level B1.

Table 6. Translation problem solving competence descriptors 
1. Can solve translation problems characteristic of semi-specialized texts (for a non-specialized target audience) corresponding to at least one area of professional practice (legal and administrative; economic and financial; technical; scientific; non-literary publishing), respecting the target language's conventions and without errors in terms of meaning.

2. Can solve problems stemming from translation briefs in professional contexts for a non-specialized target audience.

3. Can solve language interference problems.

4. Can solve basic thematic problems, and explicit and implicit cultural difference and world knowledge problems.

5. Can solve intentionality problems related to difficulties understanding information in the original text (intertextuality, presuppositions, implicature).

6. Can solve different types of translation problems according to a translation brief (equifunctional translation, informative translation, adaptation, etc.).

7. Can use appropriate strategies to solve translation problems corresponding to this level.

\subsection{Main characteristics of the proposed description}

Our description (Table 7) comprises descriptive categories (horizontally) and the

different levels' descriptors (vertically).

Table 7. Descriptive categories and performance levels

\begin{tabular}{|l|l|l|l|l|l|}
\hline & $\begin{array}{l}\text { Language } \\
\text { competence }\end{array}$ & $\begin{array}{l}\text { Cultural, world } \\
\text { knowledge and } \\
\text { thematic } \\
\text { competence }\end{array}$ & $\begin{array}{l}\text { Instrumental } \\
\text { competence }\end{array}$ & $\begin{array}{l}\text { Translation } \\
\text { service } \\
\text { provision } \\
\text { competence }\end{array}$ & $\begin{array}{l}\text { Translation } \\
\text { problem solving } \\
\text { competence }\end{array}$ \\
\hline $\begin{array}{l}\text { Translation } \\
\text { Level C }\end{array}$ & & & & & \\
\hline $\begin{array}{l}\text { Translation } \\
\text { Level B2 }\end{array}$ & & & & & \\
\hline $\begin{array}{l}\text { Translation } \\
\text { Level B1 }\end{array}$ & & & & & \\
\hline $\begin{array}{l}\text { Translation } \\
\text { Level A2 }\end{array}$ & & & & & \\
\hline $\begin{array}{l}\text { Translation } \\
\text { Level A1 }\end{array}$ & & & & & \\
\hline
\end{tabular}

We emphasize our proposed description's main characteristics below.

(1) It is intended to be of use to both the academic and professional arenas.

(2) It is independent of language combinations, directionality (direct/inverse

translation), stages of education and professional contexts, so it could be used in any educational or professional context according to the needs thereof.

(3) It does not describe the different areas of professional specialization

corresponding to level $\mathrm{C}$. The level in question is special in that each 
professional area should be described, requiring further research. We have only described level $\mathrm{C}$ in general terms.

(4) The progression established in each descriptive category is accumulative, i.e. an individual at any given level is assumed to have mastered the previous one.

(5) All the descriptive categories are interrelated. In that regard, there may be no change in a given descriptor within a category between one level and the next, but changes in the rest of the categories. The five categories interact and balance one another out to guarantee appropriate translation quality at each level (e.g. cultural, world knowledge and thematic competence and instrumental competence $)^{10}$.

(6) As our proposal is aimed at making progress in the production of a framework of reference, we have sought to word the level descriptors clearly, straightforwardly and in such a way as to ensure they are both easily observable, to facilitate their use in different academic and professional contexts, and readily intelligible to potential users of the scales (translation students and lecturers, translators, employers). Accordingly, we have not used indicators of a more cognitive nature (e.g. identify, plan, evaluate, justify, use strategies), which, while very useful from a pedagogical point of view, are more difficult to observe in professional practice. For example, the instrumental competence descriptors do not include indicators such as "plan queries" or "evaluate query results". Similarly, the cultural, world knowledge and thematic competence descriptors do not include indicators involving intercultural attitudes (e.g. having an open

9. It should be borne in mind that in professional practice the greatest emphasis tends to be placed on the result of translation (translation quality) and meeting deadlines. 
attitude towards other cultural realities, being aware of stereotypes of and prejudices towards the foreign culture in one's own culture, and empathizing with the foreign culture). In the translation problem solving competence descriptors, we have avoided indicators concerning the use of cognitive strategies to solve problems. All such indicators should be incorporated into individual curriculums according to their specific needs.

(7) As the descriptors refer to competences, they describe capabilities to act (can do) and not declarative knowledge. Our proposal also refrains from specifying degrees of translation quality for each level, as they should be defined according to each educational or professional context's needs.

(8) Our proposal does not establish or describe learning outcomes or learning tasks suited to each level (e.g. identifying problems or errors, translating key ideas, gist translation, correcting texts). While this would be particularly useful for the academic arena, doing so would require further research. In the case of level $\mathrm{C}$, the professional tasks besides translation performed in each area of specialization, such as project management, creating terminology databases, adaptation, technical writing, revision and post-editing, should be incorporated into the description. Level B2 includes professional tasks such as revising and post-editing translations, which generalist translators commonly carry out at present.

\subsection{Global scale description}

To make the descriptor scales easier to use for potential users (students, lecturers, translators, employers, etc.), and as is common practice in descriptions of level scales (see the CEFR, for example), we have produced a global scale (Table 8) that identifies the different levels' essential characteristics. Each level's first descriptor summarizes 
what and how an individual must be able to translate, and specifies the minimum CEFR reading comprehension and written production level required in the source and the target language respectively. Given its status as the central competence, there is a descriptor (the second or third, depending on the level) of translation problem solving competence on every level of the scale. Each level also has an instrumental competence descriptor, and levels B1, B2 and C have a translation service provision competence descriptor. There are no descriptors of cultural, world knowledge and thematic competence, as its use is already covered in the descriptors related to problem solving.

Table 8. Global scale

\section{TRANSLATION LEVEL C}

1. Can translate specialized texts corresponding to at least one of translation's areas of professional specialization (legal; economic and financial; technical; scientific; literary; audiovisual; accessibility; localization), to which end a minimum of CEFR reading comprehension level $\mathrm{C} 2$ in the source language and CEFR written production level $\mathrm{C} 2$ in the target language is required (particular areas of specialization may have special characteristics).

2. Can solve translation problems specific to the relevant area of professional specialization.

3. Can identify and use reliable documentation resources and use technological tools to solve the aforementioned translation problems, and can adapt to new documentation resources and technological tools.

4. Can manage aspects of professional practice and the workings of the labour market in the relevant area of professional specialization.

[To be developed further]

TRANSLATION LEVEL B2

1. Can translate semi-specialized texts (for a non-specialized target audience) corresponding to at least one area of professional practice (legal and administrative; economic and financial; technical; scientific; non-literary publishing) in situations involving professional translation for a non-specialized target audience, without errors in terms of meaning, in a manner that is linguistically correct and appropriate to the brief, to which end a minimum of CEFR reading comprehension level $\mathrm{C} 1$ in the source language and CEFR written production level $\mathrm{C} 2$ in the target language is required.

2. Can carry out different types of translations according to the brief involved.

3. Can solve language interference problems; basic thematic problems; explicit and implicit cultural difference and world knowledge problems; and intentionality problems.

4. Can identify and use reliable documentation resources and use technological tools to solve the aforementioned translation problems, and can adapt to new documentation resources and technological tools.

5. Can manage aspects of professional practice and the workings of the labour market.

\section{TRANSLATION LEVEL B1}

1. Can translate non-specialized texts corresponding to at least one area of professional practice (legal and administrative; economic and financial; technical; scientific; non-literary publishing) in situations involving professional translation for a non-specialized target audience, without errors in terms of meaning, in a manner that is linguistically correct and appropriate to the brief, to which end a minimum of CEFR reading comprehension level $\mathrm{C} 1$ in the source language and CEFR written production level C2 in the target language is required.

2. Can solve language interference problems; basic thematic problems; explicit and implicit cultural difference and world knowledge problems; and intentionality problems.

3. Can identify and use reliable documentation resources and use technological tools to solve the aforementioned translation problems. 
4. Can distinguish basic aspects related to the translation labour market.

\section{TRANSLATION LEVEL A2}

1. Can translate non-specialized texts involving problems related to register in non-professional contexts, without errors in terms of meaning, in a manner that is linguistically correct and appropriate to the brief, to which end a minimum of CEFR reading comprehension level B2 in the source language and CEFR written production level $\mathrm{C} 1$ in the target language is required.

2. Can solve language interference problems; problems stemming from language variation; explicit cultural difference and world knowledge problems; and intentionality problems.

3. Can identify and use reliable documentation resources and use technological tools to solve the aforementioned translation problems.

TRANSLATION LEVEL A1

1. Can translate different types of non-specialized texts in standard language in non-professional contexts, without errors in terms of meaning, in a manner that is linguistically correct and appropriate to the brief, to which end a minimum of CEFR reading comprehension level B2 in the source language and CEFR written production level $\mathrm{C} 1$ in the target language is required.

2. Can solve basic language interference problems and basic explicit cultural difference and world knowledge problems.

3. Can identify and use reliable documentation resources and use technological tools to solve the aforementioned translation problems.

\section{Next steps and final remarks}

June 2017 has seen the beginning of the second stage of the project's research, in which expert judgement on the proposed descriptors is to be sought. The expert evaluators will be tasked with gauging the appropriateness of the proposed levels and categories and their names, as well as the suitability of our use of text genres and their progression. They will also have to make judgements on and correct the descriptors, appraise the progression proposed for each descriptive category and the global scale, and assess the three proposed annexes.

The project will conclude with a revision of the proposed descriptors in 2018, once we have analysed the information obtained through the expert judgement process.

As stated previously, this project is merely a first step towards developing a European framework of reference for levels in translation, and there will still be much work to do when it ends. Firstly, the proposed descriptors arising from the project will need to be validated, to which end the scale's precision and the descriptors' suitability will have to be tested with a broad, representative sample of students, lecturers and professional translators. Furthermore, the different areas of professional specialization corresponding to level $\mathrm{C}$ will need to be described and validated. In a subsequent stage 
of the research it will be necessary to design and validate evaluation instruments for each level. In brief, we still have a long way to go. 


\section{References}

Council of Europe. 2001. Common European Framework of Reference for Languages (CEFRL). Strasbourg: Languages Policy Division.

—. 2016. CEFR Illustrative Descriptors. Extended Version 2016 [pilot version]. Strasbourg: Languages Policy Division.

EMT. 2009. "Competences for Professional Translators, Experts in Multilingual and Multimedia Communication." Directorate-General Translation. Accessed 18 July 2017.

http://ec.europa.eu/dgs/translation/programmes/emt/key_documents/emt_competences_ translators_en.pdf

Hurtado Albir, Amparo. (2001) 2011. Traducción y Traductología. Introducción a la Traductología. 5th ed. rev. Madrid: Cátedra.

_. , ed. 2017a. Researching Translation Competence by PACTE Group. Amsterdam: John Benjamins Publishing Company.

_ 2017b. "Translation and Translation Competence." In Investigating Translation Competence by PACTE Group, edited by Amparo Hurtado Albir, 3-35. Amsterdam: John Benjamins Publishing Company.

INCA. 2009. "The INCA Project: Intercultural Competence Assessment." INCA Project. Accessed 18 July 2017. https://ec.europa.eu/migrant-integration/librarydoc/the-incaproject-intercultural-competence-assessment

Koby, Geoffrey S., and Alan K. Melby. 2013. "Certification and Job Task Analysis (JTA): EstablishingValidity of Translator Certification Examinations." Translation \& Interpreting 5 (1): 174-201.

NAATI. 2016. "Improvements to NAATI Testing (INT)." NAATI. Accessed 18 July 2017. https://www.naati.com.au/projects/improvements-to-naati-testing-int/.

PACTE. 2000. “Acquiring Translation Competence: Hypotheses and Methodological Problems in a Research Project." In Investigating Translation, edited by Allison Beeby, Doris Ensinger, and Marisa Presas, 99-106. Amsterdam: John Benjamins.

_ 2003. "Building a Translation Competence Model.” In Triangulating Translation: Perspectives in Process Oriented Research, edited by Fábio Alves, 43-66. Amsterdam: John Benjamins. 
_ 2014. "First Results of PACTE Group's Experimental Research on Translation Competence Acquisition: The Acquisition of Declarative Knowledge of Translation.” MonTI : Monografias de Traducción E Interpretación, no. special issue 1: 85-115.

—. 2015. "Results of PACTE's Experimental Research on the Acquisition of Translation Competence: The Acquisition of Declarative and Procedural Knowledge in Translation. The Dynamic Translation Index.” Translation Spaces 4 (1): 29-53.

—. In press. "Establecimiento de niveles de competencias en traducción. Primeros resultados del proyecto NACT." Onomazein 43.

- Submitted. "Evolution of the Efficacy of the Translation Process in Translation Competence Acquisition. Results of the PACTE Group's Experimental Research.”.

PICT. 2012. "Intercultural Competence. Curriculum Framework." Promoting Intercultural Competence in Translators. Accessed 18 July 2017. http://www.pictllp.eu/download/curriculum/PICT-CURRICULUM_ENGLISH.pdf.

Skills CFA. 2007. “Translation.” UK's National Occupational Standards. Accessed 18 July 2017. www.skillscfa.org/standards-qualifications/language-intercultural.

Vertaalacademie Maastricht, and PSTEVIN. 2016. "Competences”. Unpublished work.

Yarosh, Maria. 2012. "Translator Intercultural Competence: The Concept and Means to Measure the Competence Development." (PhD diss., University of Deusto).

—. 2015. "Translator Intercultural Competence: A Model, Learning Objectives, and Level Indicators." In Handbook of Research on Teaching Methods in Language Translation and Interpretation, edited by Ying Cui and Wei Zhao, 160-78. Hershey: IGI Global. 


\section{Annex 1. Examples of text genres liable to be translated}

\begin{tabular}{|l|}
\hline TRANSLATION LEVEL C \\
\hline Text genres corresponding to areas of professional specialization \\
Legal \\
Laws, decrees, regulations and statutes; complaints, claims, lawsuits, requests, rulings, orders, judgements, \\
official letters, warrants, notifications, summons, foreclosures, expert reports; deeds, contracts (franchise \\
agreements, contracts awarded through competitive bidding processes, business transfer agreements, \\
options and futures contracts), powers of attorney, wills, acknowledgements of debt; learning guides, \\
research articles, monographs, theses, lectures/papers.
\end{tabular}

- Economic and financial

Investment plans; financial reports, credit reports, financial rating reports; annual profit and loss accounts; annual reports; finance contracts; banking products; balance sheets; tax returns; business plans, specifications for tendering, insurance policies, quotes, valuations, reinsurance contracts, advertising texts on forms of reinsurance, learning guides, research articles, monographs, theses, lectures/papers.

- Scientific

Clinical reports, drug catalogues, information for prescribers, clinical trial protocols, applications for research funding, regulations, medical reports, medical certificates, clinical trials, research reports, learning guides, research articles, monographs, theses, lectures/papers.

- Technical

Production plans, minutes of technical meetings, part lists, product development requests, patents, technical standards and guarantees, energy balances, technical certificates, labour standards, technical projects, articles published in company magazines, technical specifications, learning guides, research articles, monographs, theses, lectures/papers.

\section{- Literary}

Comics; didactic literature (adages, sayings, maxims, proverbs); narrative (legends and fables, stories, novels); theatre (comedies, tragedies, dramas); poetry (dramatic, lyric, epic); opera libretti; essays, monographs, theses.

- Audiovisual

- Voice-over: documentaries, reports, advertorials, interviews, debates, reality shows, films.

- Dubbing: documentaries, reports, advertorials, cartoons, series and telefilms, soap operas, films, filmed theatre, filmed operas, advertising texts, public information or prevention campaigns, party election broadcasts, entertainment programmes (cooking, DIY, gardening, gymnastics, etc.), children's programmes, humour programmes, music programmes.

- Subtitling: news, documentaries, reports, advertorials, films, advertising texts, interviews, debates, talk shows, filmed theatre, filmed operas, public information or prevention campaigns, party election broadcasts, informative cultural programmes.

- Accessibility

- Audio description: cartoons; children's programmes; films for DVD, television or cinemas; theatre, filmed theatre, operas, filmed operas, music and dance shows; documentaries, reports, advertorials; informative cultural programmes; public information or prevention campaigns, etc.; party election broadcasts; museum audio guides; urban audio description (tactile maps, tower viewers, digital advertising panels, etc.); location and movement systems (such as GPS) (for urban routes, gardens, hospitals, museums, etc.); descriptions of everyday situations (classes, meetings, etc.); web or multimedia products (images, diagrams, logos, etc.). - Subtitling for the deaf: cartoons; children's programmes; films; theatre, filmed theatre, operas, filmed operas; documentaries, reports, advertorials; informative cultural programmes; public information or prevention campaigns; party election broadcasts; advertising texts; competitions; subtitles for everyday situations (classes, meetings, etc.); television series.

- Localization

Web pages, software, videogames, applications for mobiles, demos. 

specialized target audience)

- Legal and administrative

Contracts (employment contracts, lease agreements, rental agreements, etc.); sworn statements; signature certification; legal letters; reports, advertorials; lectures; learning guides; explanatory articles/books; curriculums.

- Economic and financial

bills; advertising texts (for investment funds, risk cover, exchange-traded fixed income, investment financing, stock market investment, deposits, etc.); press releases; payslips; bank account statements; income tax returns; purchase orders; debit notes; reports, advertorials; lectures; learning guides; explanatory articles/books; curriculums.

- Technical

Advertising texts; reports, advertorials; lectures; learning guides; explanatory articles/books; curriculums.

- Scientific

Patient information leaflets; informed consent forms; health leaflets; advertising texts; reports, advertorials; lectures; learning guides; explanatory articles/books; curriculums.

- Non-literary publishing

Essays (historical, philosophical, literary, biographical, political, etc.), mass-market paperbacks (western novels, romance novels, detective novels); film scripts; reports, lectures, learning guides, explanatory articles/books, curriculums related to publishing.

\section{Non-specialized text genres corresponding to different areas of professional practice}

- Legal and administrative

Certificates (academic certificates, birth, death and marriage certificates, residence cards, certificates of municipal registration, criminal record certificates, etc.); work permits; reports, advertorials; secondary school textbooks; general encyclopaedia entries; explanatory articles/books.

- Economic and financial

Bills for everyday products; advertising texts for insurance products (life insurance, civil liability insurance, multi-risk insurance, etc.), banking products (pension plans, bank deposits, accounts, personal loans); reports, advertorials; secondary school textbooks; general encyclopaedia entries; explanatory articles/books.

- Technical

Instruction manuals; product catalogues (lawnmowers, food processors, ovens, etc.); reports, advertorials; secondary school textbooks; general encyclopaedia entries; explanatory articles/books.

- Scientific

Patient information leaflets; health information campaigns; product catalogues (nutritional supplements, animal feed, wines, insecticides, etc.); reports, advertorials; general encyclopaedia entries; secondary school textbooks; explanatory articles/books.

- Non-literary publishing

Journalistic literature (reports, advertorials, interviews, journalistic accounts); general encyclopaedia entries; secondary school textbooks; explanatory articles/books.

\section{TRANSLATION LEVEL A2}

Non-specialized text genres with different registers (tenor, style)

- Narrative

Biographical encyclopaedia entries; history books; press articles (describing an event, a biography, etc.); stories.

- Descriptive

Tourist brochures; tourist guides; reports (on a place, a person, a style of music, a group of people, etc.); descriptions of organizations (companies, international bodies, associations, etc.), courses and products.

- Expository

Encyclopaedia entries on general subjects (global warming, the big bang theory, forest conservation, etc.); explanatory textbooks (on Translation Studies, Linguistics, Philosophy, etc.). 
- Argumentative

Letters of complaint; film reviews; opinion pieces on general subjects.

- Instructional

Recipes; instructions used in everyday life (first aid, games, physical exercise, crafts, etc.); advertising texts (for a product, an event, a service, etc.); fables.

\section{TRANSLATION LEVEL A1}

\section{Non-specialized text genres in standard language corresponding to different text types}

- Narrative

Biographical encyclopaedia entries; history books; press articles (describing an event, a biography, etc.); stories.

- Descriptive

Tourist brochures; tourist guides; reports (on a place, a person, a style of music, a group of people, etc.); descriptions of organizations (companies, international bodies, associations, etc.), courses and products.

- Expository

Encyclopaedia entries on general subjects (global warming, the big bang theory, forest conservation, etc.); explanatory textbooks (on Translation Studies, Linguistics, Philosophy, etc.).

- Argumentative

Letters of complaint; film reviews; opinion pieces on general subjects.

- Instructional

Recipes; instructions used in everyday life (first aid, games, physical exercise, crafts, etc.); advertising texts (for a product, an event, a service, etc.); fables.

\section{Annex 2. Examples of cultural and world knowledge}

\section{TRANSLATION LEVEL C}

Cultural, world and thematic knowledge required in professional practice.

$$
\text { [To be developed further] }
$$

[Same as B1]

\section{TRANSLATION LEVEL B2}

\section{TRANSLATION LEVEL B1}

Knowledge of the foreign culture comparable to secondary education level in the culture in question in the following areas:

- Environment. E.g. geographical features, cities, climate, flora and fauna.

- Cultural heritage. E.g. historical events, religious beliefs, monuments, celebrations and traditions, art and literature.

- Social organization. E.g. customs; political system, legal system, education system, etc.; territorial organization; units of measurement.

- Models of behaviour, values and ideas. E.g. individualism vs. collectivism; management of emotions, time and space; social and gender equality vs. inequality; empathy with other social groups.

Advanced knowledge of one's own culture in the following areas:

- Environment. E.g. geographical features, cities, climate, flora and fauna.

- Cultural heritage. E.g. historical events, religious beliefs, monuments, celebrations and traditions, art and literature.

- Social organization. E.g. customs; political system, legal system, education system, etc.; territorial organization; units of measurement.

- Models of behaviour, values and ideas. E.g. individualism vs. collectivism; management of emotions, time and space; social and gender equality vs. inequality; empathy with other social groups.

Advanced universal world knowledge in the following areas:

- Environment. E.g. geographical features, cities, climate, flora and fauna.

- Cultural heritage. E.g. historical events, religious beliefs, monuments, celebrations and traditions, art and literature. 
- Social organization. E.g. customs; political system, legal system, education system, etc.; territorial organization; units of measurement.

Basic thematic knowledge in at least one of the following fields: legal and administrative; economic and financial; technical; scientific.

TRANSLATION LEVEL A2

[Same as A1]

TRANSLATION LEVEL A1

Knowledge of basic aspects of the foreign culture in the following areas:

- Environment. E.g. geographical features, cities, climate, flora and fauna.

- Cultural heritage. E.g. historical events, religious beliefs, monuments, celebrations and traditions.

- Social organization. E.g. customs; political system, legal system, education system, etc.; units of measurement.

Knowledge of one's own culture comparable to secondary education level in the following areas:

- Environment. E.g. geographical features, cities, climate, flora and fauna.

- Cultural heritage. E.g. historical events, religious beliefs, monuments, celebrations and traditions, art and literature.

- Social organization. E.g. customs; political system, legal system, education system, etc.; territorial organization; units of measurement.

- Models of behaviour, values and ideas. E.g. individualism vs. collectivism; management of emotions, time and space; social and gender equality vs. inequality; empathy with other social groups.

General universal world knowledge comparable to secondary education level in the following areas:

- Environment. E.g. geographical features, cities, climate, flora and fauna.

- Cultural heritage. E.g. historical events, religious beliefs, monuments, celebrations and traditions, art and literature.

- Social organization. E.g. customs; political system, legal system, education system, etc.; territorial organization; units of measurement.

\section{Annex 3. Examples of technological tools and functions}

TRANSLATION LEVEL C

Mastery of advanced functions of the tools specific to the relevant area of professional specialization. [To be developed further]

Mastery of specialized technological tools and their basic functions:

- Specialized search engines: perform a query, refine a search, search by media type, perform a query using Boolean operators, refine a search by restricting criteria, use the search engine's cache, etc.

- Computer-assisted translation tools: create a translation project, import and export translation memories, analyse a text, pretranslate a text, propagate translations from a memory, use a program's revision tools, create terminology databases, etc.

- Text alignment tools: define the level of segmentation, align documents, export an alignment, create a translation memory from an alignment, etc.

- Corpus linguistics tools applied to translation: create term lists, search for collocations, extract concordances and frequency lists, create a corpus, etc.

- Accounting and budgeting tools (if required in the relevant area of professional practice): create customer records, perform word counts, create quotes and invoices, organize invoices, record taxes on goods and services, track invoices issued, etc.

\section{TRANSLATION LEVEL B1}

Mastery of advanced technological tools and their basic functions:

- Document conversion tools: prepare a document for character recognition, export a converted document, edit a converted document, etc.

TRANSLATION LEVEL A2

Mastery of basic technological tools and their advanced functions: 
- Text processors: apply and modify styles, use advanced revision tools, compare documents, customize toolbars, create macros, create tables of contents, headers, cross-references, etc.

- General online search engines: perform a query using Boolean operators, refine a search by restricting criteria, use the search engine's cache, etc.

\section{TRANSLATION LEVEL A1}

Mastery of basic technological tools and their basic functions:

- Text processors: open, save and format documents, use search and replace functions, use spellcheckers, modify page design, etc.

- General online search engines: perform a query, refine a search, search by media type (e.g. web pages, images, videos), etc.

- Email clients: create folders, create filters, configure email tracking, group emails together in threads, create rules for spam, etc. 